\title{
Deepest Chess Win Revisited
}

\author{
Article
}

Published Version

Haworth, G. M. (2000) Deepest Chess Win Revisited. ICGA Journal, 23 (2). pp. 94-96. ISSN 1389-6911 Available at https://centaur.reading.ac.uk/4567/

It is advisable to refer to the publisher's version if you intend to cite from the work. See Guidance on citing.

Published version at: http://ticc.uvt.nl/icga/journal/

Publisher: The International Computer Games Association

All outputs in CentAUR are protected by Intellectual Property Rights law, including copyright law. Copyright and IPR is retained by the creators or other copyright holders. Terms and conditions for use of this material are defined in the End User Agreement.

\section{www.reading.ac.uk/centaur}

\section{CentAUR}

Central Archive at the University of Reading

Reading's research outputs online 


\title{
DEEPEST CHESS WIN REVISITED
}

\author{
G.MCC. Haworth ${ }^{1}$
}

UK

Thompson's renewed contribution to the available suite of chess endgame tables (EGTs) is very welcome. A request for a KQQKQQ EGT (Nalimov, Wirth and Haworth, 1999) apparently arrived coincidentally and just before production recommenced. Some 50 EGTs (Thompson, 1999) dating from $26^{\text {th }}$ November, 1999 are now available.

For KRNKNN Thompson (2000), at Noam Elkies' suggestion, computed both his usual EGT according to the Depth to Conversion (DTC) metric and an EGT according to the Depth to Mate (DTM) metric. The depth record for forced mate with no promoted men beckoned and was achieved with the unique DTM-maximal P2 of Table 1. Ken in his own words "held the record for 15 minutes" as Elkies produced the preliminary P1 with the move sequence 1. Rg3+ K×g3 2. Ne2+ Kg2 3. N×g1 K×g1. Elkies suggests that the record, at 265 moves, is beatable.

\begin{tabular}{|c|c|c|c|c|c|c|c|}
\hline Key & Position & stm & Val. & DTZ & DTC & DTM & Notes \\
\hline & & & & plies & plies & plies & \\
\hline BS1 & 8/8/1KP5/3r4/8/8/8/k7 & $\mathrm{w}$ & $1-0$ & 1 & 11 & 51 & the Barbier-Saavedra study \\
\hline BS2 & 8/2P5/8/3r4/1K6/8/8/k7 & $\mathrm{b}$ & $1-0$ & 6 & 6 & 46 & BS1 after 1. c7 Rd6+ 2. Kb5 Rd5+ 3. Kb4 \\
\hline $\mathrm{C} 1$ & 6Q1/8/8/1n6/8/7K/7B/k6B & $\mathrm{w}$ & $1-0$ & 2 & 2 & 7 & DTC: 1. Qa2? Kxa2 and DTC = 52. DTM: 1. Be5+ ... \\
\hline $\mathrm{C} 2$ & $\mathrm{R} 7 / 8 / 8 / 8 / 8 / 8 / 1 \mathrm{~B} 1 \mathrm{~K} 4 / \mathrm{k} 7$ & $\mathrm{~b}$ & $1-0$ & 2 & 2 & 12 & DTC: 1 .... Kb1 2. Ra1\#. DTM: 1 ... Kxb2 and DTM = 6m \\
\hline P1 & 1N6/1RK5/5n2/8/8/3R4/5nk1/2N3q1 & $\mathrm{W}$ & $1-0$ & 2 & 2 & 529 & Elkies maximal 'no promoted force' mate in $265 \mathrm{~m}$ \\
\hline $\mathrm{P} 2$ & 1N6/1RK5/5n2/8/8/8/5n2/6k1 & $\mathrm{w}$ & $1-0$ & 485 & 485 & 523 & the maxDTC/DTM wtm KRNKNN position \\
\hline P3 & 1N6/1R6/3K1n2/8/8/8/5n2/6k1 & $\mathrm{b}$ & $1-0$ & 484 & 484 & 522 & P2 after 1. Kd6: a maxDTC/DTM btm KRNKNN pos. \\
\hline P4 & 8/5R2/1k6/4N3/2Kn4/1n6/8/8 & $\mathrm{b}$ & $1-0$ & 8 & 8 & 42 & P2 after 241. Rf7 threatening 242. Nd7 \\
\hline Q1 & 7K/3q4/8/3q4/8/7Q/1k5Q/8 & $\mathrm{b}$ & $1-0$ & 88 & 88 & 100 & the maxDTC/DTM btm KQQKQQ position \\
\hline Q2 & 7K/3q4/8/3q4/8/7Q/7Q/1k6 & $\mathrm{w}$ & $1-0$ & 87 & 87 & 99 & the maxDTC/DTM wtm KQQKQQ position \\
\hline Q3 & 8/4q3/8/6k1/2Q5/2K5/Q7/7q & $\mathrm{w}$ & $1-0$ & 81 & 81 & 99 & the other maxDTM wtm KQQKQQ position \\
\hline
\end{tabular}

Table 1: Cited positions.

As Roycroft (2000) points out, Thompson's results may be put alongside those of Stiller (1996) which are confirmed if no longer available in full. The existence of both a DTC and a DTM table provides a hitherto rare opportunity to highlight the fact that the set of maximal positions as well as the set of minimax-optimal moves (Haworth, 2000) may or may not be affected by the metric used.

The description of the KRNKNN maximals is relatively simple. With White to move, P2 is both the unique DTCmaximal and the unique DTM-maximal. There are 7 DTM-maximal btm white wins, including P3, which are one ply shallower. In general, the statement about maximals can be more complex. At 50 moves deep, KQQKQQ (Nalimov et al, 1999) exhibits Q1 and Q2, both DTC- and DTM-maximal, plus a further DTM-maximal in Q3. Incidentally, all 3-to-5-man EGTs to both the DTC (Lincke, 2000) and DTM (Tamplin, 2000) metrics are now available and a complete survey of maximals and mutual zugzwangs is imminent.

Roycroft (2000) notes that with an $a \leftrightarrow h$ reflection, Stiller's maximal KRNKNN position and DTC-minimaxing line are essentially identical to Thompson's DTM-minimaxing line up to and including move 109w. This observation complements that of Haworth (2000) which noted that the DTC-minimaxing and DTM-minimaxing trees of moves from position P2 overlap to at least move 207w. The earliest possible and latest possible moves where DTCoptimal and DTM-optimal strategies respectively can and must diverge have not yet been identified.

\footnotetext{
${ }^{1}$ ICL, Sutton’s Park Avenue, Sutton’s Park, Reading, Berkshire, RG6 1AZ, UK: guy.haworth@icl.com
} 


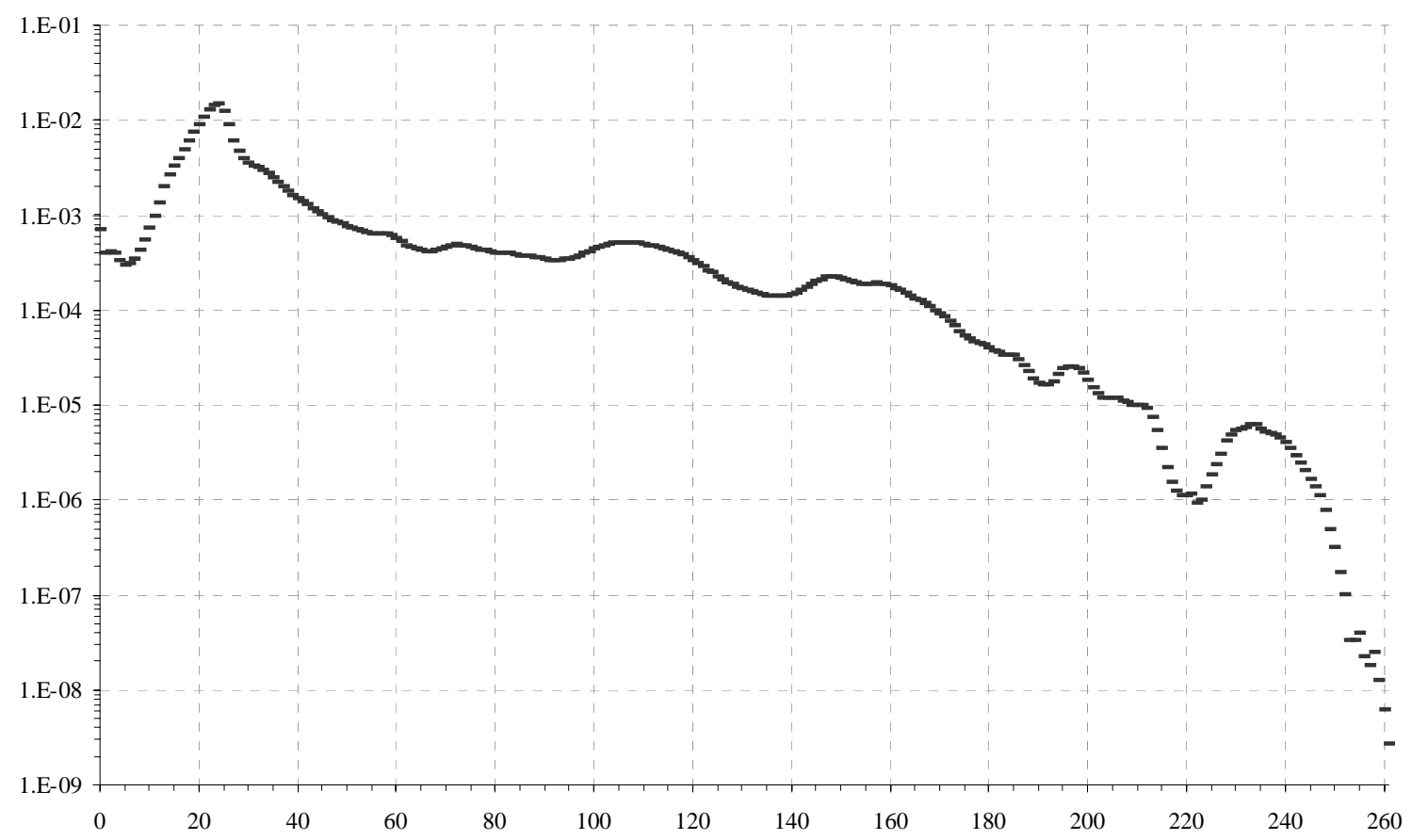

Table 2: Fraction of btm positions won by White with DTM $=x$.

Comparing Thompson's and Stiller's lines in detail, the first equi-optimal choices (all 2-way and both DTC- and DTM-equi-optimal) are on moves 15w, 26b, 28w, 65w, 76b and 109b. Thompson chose the opposite move to Stiller on moves 15w and 26b, re-converged on the following moves and finally diverged on move 109.

Tables 2 and 3 are derived from Nalimov's DTM statistics (Hyatt, 2000) and use a logarithmic axis to present the information more clearly. In the typical long-tailed distribution by depth, they show the extreme rarity of the deeper positions. It is perhaps not surprising then that, in the deepest parts of the EGT, White has few winning, let alone equi-optimal, options. In contrast, a fallible Black has a persistent opportunity to lose depth in large amounts and would be expected to foreshorten the endgame play.

Roycroft (2000) correctly notes that in position P4 a human player would not choose Thompson's 241. ... Ne6 and that such prima facie anomalies are inevitable irrespective of the metric being used. Computers with a minimax strategy assume an infallible opponent, are effectively 'paid by the ply' and give no weight to any other objective than longevity. Human players, for whom "hope springs eternal in the human breast" (Pope, 1734), assume the opponent is fallible and can be lured into a mistake if the likelihood of error is maximised in terms of some opponent model. In this spirit, Barth (1995a, 1995b) refers to "study-like" positions and did not (Edwards, 1995) focus only on DTM-optimal moves. Study composers, active of course before EGTs were available, choose the best defence for Black which typically leaves one, preferably obscure, winning move for White.

The famous Barbier-Saavedra study BS1 (Barbier, 1895) provides an interesting benchmark for comparing DTC, DTM and 'human' play. At position BS2 after 3. Kb4, DTM-optimisation dictates 3. ... Kb2, effectively abject surrender: the study choice 3. ... Rd4+ is DTC-optimal but 3 moves shallower in DTM terms. After 4. Kb3 [Kc3] Rd3+ 5. Kc2, the study's 5. ... Rd4! tempting 6. c8=Q?? is merely DTC-equi-optimal with 14 other moves and 11 moves shallower than the DTM-optimal 5. ... Rf3 which again offers no resistance. The power of 5. ... Rd4! is not its associated depth but the apparently decisive white Queen which is not on the board.

The DTM metric leads to more 'unnatural' play from BS2 and supports Thompson's preference for the DTC metric. However, DTC leads to unnatural play in C1 and C2 where DTM play is natural. Haworth (2000) also showed that blind use of either DTC or DTM can turn a win into a 50-move draw. In short, both metrics have their advantages and adherents and will continue to be favoured by respective EGT authors. 


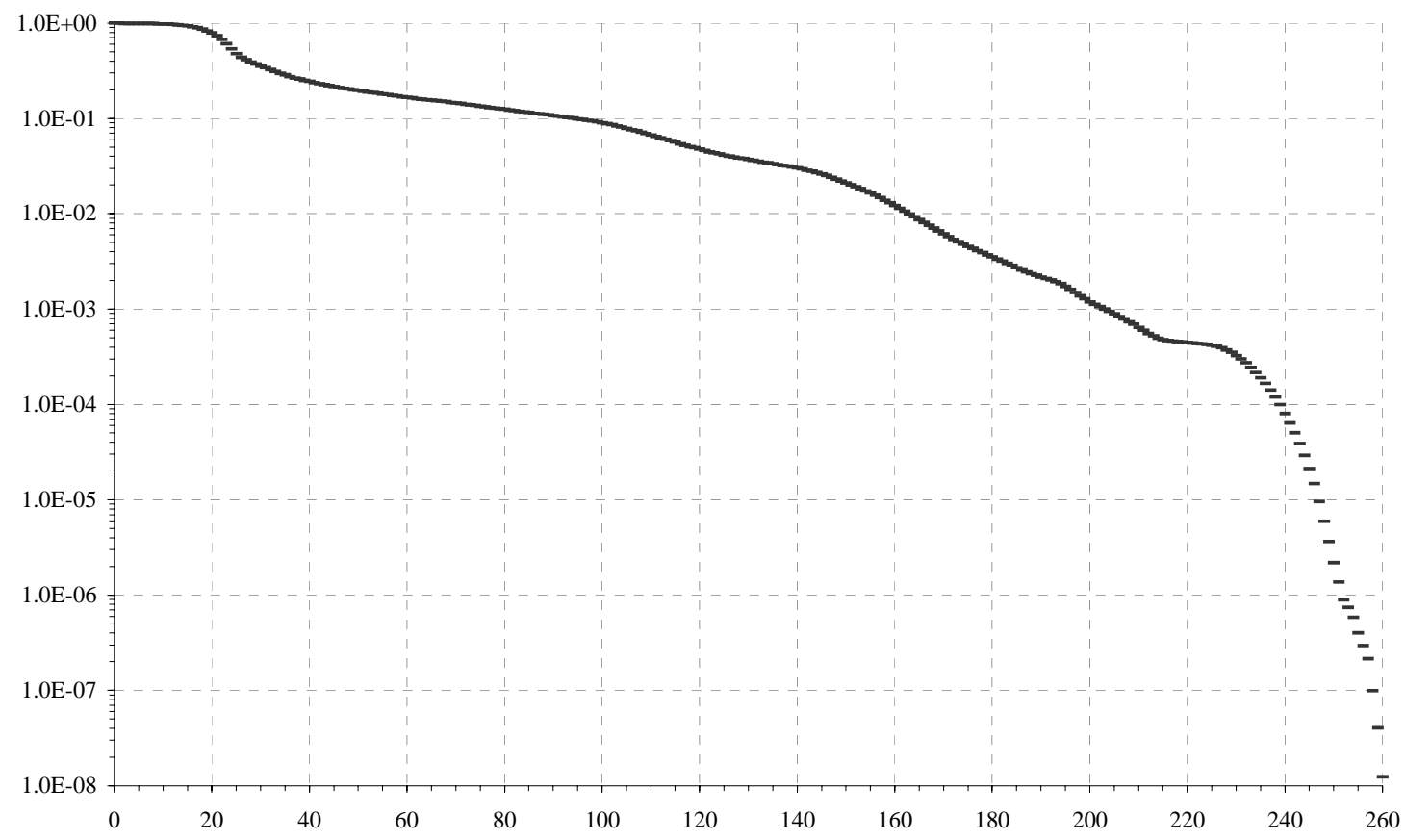

Table 3: Fraction of btm white wins with DTM $>x$.

\section{REFERENCES}

Barbier, G.E. (1895). The Barbier-Saavedra study. Glasgow Weekly Citizen, $4^{\text {th }} \& 18^{\text {th }}$ May.

Barth, W. (1995a). Combining Knowledge and Search to Yield Infallible Endgame Programs. A Study of Passed Pawns in the KPKP Endgame. ICCA Journal, Vol. 18, No. 3, pp. 149-159.

Barth, W. (1995b). The KPKP Endgame: An Amplification. ICCA Journal, Vol. 18, No. 4, pp. 225-226.

Edwards, S.J. (1995). Comments on Barth's Article "Combining Knowledge and Search to Yield Infallible Endgame Programs.” ICCA Journal, Vol. 18, No. 4, p. 219-225.

Haworth, G.Mc C. (2000). Strategies for Constrained Optimisation. ICGA Journal, Vol. 23, No. 1, pp. 9-20.

Hyatt, R. (2000). ftp://ftp.cis.uab.edu/pub/hyatt/TB/. Server providing Nalimov's EG DTM statistics and tables.

Lincke, T. (2000). http://nobi.inf.ethz.ch/games/chess. Browser for 3-to-5-man DTC EGTs.

Nalimov, E., Wirth, C. and Haworth, G.M ${ }^{\mathrm{c} C}$. (1999). KQQKQQ and the Kasparov-World Game. ICCA Journal, Vol. 22, No. 4, pp. 195-212.

Pope A. (1733-1734). An Essay on Man, Epistle I. Dover Publications (1994). ISBN 0-4862-8053-5.

Roycroft, A.J. (2000). Private communication to the ICGA J editor.

Stiller, L.B. (1996). Multilinear Algebra and Chess Endgames. Games of No Chance (ed. R.J. Nowakowski), pp. 151-192. MSRI Publications, Vol. 29, CUP, Cambridge, England. ISBN 0-521-64652-9.

Tamplin, J. (2000). http://chess.liveonthenet.com/chess/endings/index.shtml. Position evaluations via Nalimov's 3to-6-man DTM EGTs.

Thompson, K. (1999). Thompson, K. (2000). http://cm.bell-labs.com/cm/cs/who/ken/chesseg.html. 6-man EGT maximal positions, maximal mutual zugzwangs and endgame statistics.

Thompson, K. (2000). The Longest: KRNKNN in 262. ICGA Journal, Vol. 23, No. 1, pp. 35-36. 